\title{
The correlation between full biophysical profile and rapid biophysical profile in antepartum fetal surveillance
}

\author{
Akshay Vedanga Prabhu, Nina Mahale*, Ajit Mahale
}

Department of Obstetrics \& Gynecology, Kasturba medical college, Mangalore, India

Received: 27 May 2015

Accepted: 06 June 2015

\author{
*Correspondence: \\ Dr. Nina Mahale, \\ E-mail: mahalenina@gmail.com
}

Copyright: () the author(s), publisher and licensee Medip Academy. This is an open-access article distributed under the terms of the Creative Commons Attribution Non-Commercial License, which permits unrestricted non-commercial use, distribution, and reproduction in any medium, provided the original work is properly cited.

\begin{abstract}
Background: The aim of this study was to assess the efficiency of rapid biophysical profile in antepartum fetal surveillance and ability to predict adverse perinatal outcome and to compare it with the gold standard full biophysical profile. The objective was to determine the correlation between the rapid biophysical profile (RBP) and the full biophysical profile (FBP) and to compare the individual scores with pregnancy outcomes.

Methods: A prospective study was performed in 153 singleton pregnancies with no fetal anomalies between 34-42 weeks of gestation. All participants received both the standard (FBP) and the new RBP. Abnormal fetal test was defined as having a score of $\leq 6$ for FBP or $\leq 2$ for RBP. The main outcome measured was Spearman's correlation coefficient (rs) between both examinations and also between each examination and pregnancy outcomes measured in terms of Apgar scores and NICU (Neonatal Intensive Care Unit) admissions

Results: The data showed a positive correlation between the two tests $(r s=0.62 ; p<0.0001)$. Out of the individual biophysical variables, only NST (Non Stress Test) had a positive correlation with RBP. The sensitivity, specificity, positive predictive value and negative predictive value of RBP in predicting adverse outcomes was found to be $71.4 \%, 87.1 \%, 35.7 \% .96 .8 \%$ respectively.

Conclusions: The statistically significant positive correlation between RBP and FBP has been revealed. Due to its simplicity, rapidity, and no need for experienced interpreter, the RBP may be alternatively used as a primary screening antepartum fetal test in the overcrowded obstetric center.
\end{abstract}

Keywords: Rapid biophysical profile, Sound provoked fetal movements, Antepartum surveillance

\section{INTRODUCTION}

Antepartum fetal surveillance, one of the most common, essential and challenging examinations in obstetric care is composed of many techniques such as contraction stress test (CST), non- stress test (NST), and fetal biophysical profile (FBP). The use of CST is obsolete in present day obstetric practice. NST remains the most widely used method due to its simple and non-invasive technique with only a few limitations. It works on the principle of fetal heart rate (FHR) accelerations in response to fetal movement in a quiescent uterus and abnormal result represents acute fetal hypoxia. Nevertheless, its high false positive rate, considerably long duration, high cost, and lack of experienced interpreters make NST a non-ideal fetal test. Fetal biophysical profile (FBP), the combination of NST and four fetal ultrasound parameters, was first introduced by Manning et a1. ${ }^{1}$ This more accurate and lower false positive rate technique has been performed by evaluating five fetal biophysical factors including fetal breathing, fetal tone, fetal gross body movements, NST and amniotic fluid index (AFI). However, FBP is reserved for only a limited number of patients due to the requirement of equipment, welltrained sonologists, and adequate examination time (at least 30 minutes). Therefore, many investigators have put in a lot of effort to develop a simple, rapid, and reliable fetal test to use as a screening tool. Rapid biophysical profile (RBP) described by AFI measurement with 
sound-provoked fetal movement (SPFM) test has been proposed by many researchers as a promising technique for fetal surveillance. ${ }^{2,3}$ Despite the extensive use of RBP, the study of the correlation between RBP and FBP is very limited. Hence, the present study analysed the correlation between the two tests in terms of abnormal and normal test detection and also with adverse perinatal outcomes.

\section{METHODS}

After the approval of the Institute's Ethics Committee, 153 pregnant women who met the inclusion criteria of singleton high risk pregnancies between $34-42$ weeks gestational age were invited to join the study. Multiple pregnancies and anomalous fetuses were excluded. The indications for fetal surveillance were hypertensive disorders of pregnancy, prolonged pregnancy, gestational diabetes mellitus, decreased fetal movements, fetal growth restriction. Informed consent was taken from all the participants. The study was designed in such a way that all participants received both FBP and RBP. NST was performed in all patients and then the remaining fetal ultrasound parameters (AFI, fetal breathing, fetal tone, and fetal movement) were examined to complete the FBP test. After a 10 minute break, SPFM was carried out by the same examiner to finish the RBP test. The obstetric care absolutely relied on the result obtained by the gold standard FBP technique.

The patient was made to lie down in the supine position and Doppler transducer (Edan fetal monitor model F3, Germany) applied to the maternal abdomen to record the FHR. In case no FHR accelerations occurred in 20 minutes, the recording was extended up to 40 minutes. The FHR tracing was considered reactive if 2 or more accelerations occurred in 20 minutes. If the criterion was not met even in 40 minutes or significant decelerations occur during this period, the test was interpreted as nonreactive.

The AFI and fetal biophysical variables were evaluated using real time scanner (Philips HD7XC) with a $5 \mathrm{MHz}$ abdominal transducer. To obtain AFI, the uterus was divided into 4 equal quadrants, then the transducer was placed along the maternal longitudinal axis and held perpendicular to the floor. AFI was calculated by adding the vertical, cord free depth of the largest amniotic fluid pocket in each quadrant. The other fetal biophysical variables (fetal breathing, gross body movements and tone) was observed subsequently during the examination.

The SPFM was performed 10 minutes after completion of FBP by the same examiner. With the help of a fetal acoustic stimulator (Maestros, Fetal stimulator HX1, 80 $\mathrm{MHz}$ ) a sound stimulus of $110 \mathrm{db}$ was applied to the abdomen near the position of fetal head for a maximum of 3 seconds and the appearance of fetal movement were looked for on the screen of ultrasound machine. If movement occurred within 15 seconds of the application of stimulus the result was said to be response or normal. If movement does not occur within 15 seconds the stimulus can be repeated up to 3 times before terming the test abnormal or no response.

According to Manning et al, ${ }^{1}$ each of five biophysical variables has a possible score of 2 , for a total of 10 . The FBP scoring system is shown in Table 1 . The score of $\leq 6$ is said to be abnormal for FBP and indicates fetal hypoxia. For RBP, the scoring system used is shown in Table 2. The RBP score of 4, characterizes the reassuring fetal circumstance while the score of $\leq 2$ represents the non-reassuring fetal status.

Table 1: Full BPP scoring system [modified from Manning et al. $\left.{ }^{1}\right]$.

\begin{tabular}{|c|c|c|}
\hline $\begin{array}{l}\text { Biophysical } \\
\text { variable }\end{array}$ & $\begin{array}{l}\text { Normal } \\
(\text { score }=2)\end{array}$ & $\begin{array}{l}\text { Abnormal } \\
(\text { score }=0)\end{array}$ \\
\hline $\begin{array}{l}\text { Fetal breathing } \\
\text { movements } \\
(\text { FBM })\end{array}$ & $\begin{array}{l}\text { One or more } \\
\text { episodes of } \\
\text { FBM>30 sec } \\
\text { in } 30 \mathrm{~min}\end{array}$ & $\begin{array}{l}\text { Absent or no } \\
\text { episode of } \\
\text { FBM>30 sec in } \\
30 \mathrm{~min}\end{array}$ \\
\hline $\begin{array}{l}\text { Gross body } \\
\text { movements }\end{array}$ & $\begin{array}{l}3 \text { or more } \\
\text { discrete body/ } \\
\text { limb movements } \\
\text { in } 30 \text { minutes } \\
\text { (episodes of } \\
\text { active } \\
\text { continuous } \\
\text { movement } \\
\text { considered as } \\
\text { single } \\
\text { movement) }\end{array}$ & $\begin{array}{l}2 \text { or less } \\
\text { episodes of } \\
\text { body/ limb } \\
\text { movements in } \\
30 \text { min }\end{array}$ \\
\hline Fetal tone & $\begin{array}{l}1 \text { or more } \\
\text { episodes of } \\
\text { extremity } \\
\text { extension and } \\
\text { subsequent } \\
\text { flexion: } \\
\text { opening and } \\
\text { closing of } \\
\text { hand } \\
\text { considered } \\
\text { normal } \\
\text { tone }\end{array}$ & $\begin{array}{l}\text { Either slow } \\
\text { extension } \\
\text { with return to } \\
\text { partial flexion } \\
\text { or movement } \\
\text { of limb in } \\
\text { full extension } \\
\text { or absent fetal } \\
\text { movements }\end{array}$ \\
\hline NST & $\begin{array}{l}2 \text { or more } \\
\text { accelerations of } \\
15 \text { beats per } \\
\text { minute for } 15 \\
\text { sec within } 20-40 \\
\text { min }\end{array}$ & $\begin{array}{l}0 \text { or } 1 \\
\text { acceleration } \\
\text { within } 20- \\
40 \text { min }\end{array}$ \\
\hline AFI & $>5 \mathrm{~cm}$ & $<5 \mathrm{~cm}$ \\
\hline
\end{tabular}

\section{Interpretation}

Score $=8-10$ Normal fetus

Score $=6$ Fetal hypoxia is suspicious

Score $=0-4$ Fetal hypoxia 
Table 2: Rapid BPP scoring system. ${ }^{4}$

\begin{tabular}{|lll|}
\hline $\begin{array}{l}\text { Biophysical variable } \\
\text { Sound provoked fetal } \\
\text { movement }\end{array}$ & $\begin{array}{l}\text { Normal } \\
(\text { score }=2)\end{array}$ & $\begin{array}{l}\text { Abnormal } \\
(\text { score }=0)\end{array}$ \\
\hline AFI & $>5 \mathrm{~cm}$ & No response \\
\hline Total score & 4 & 2 \\
\hline
\end{tabular}

\section{Interpretation}

Score $=4$ Normal fetus

Score $=0-2$ Fetal hypoxia

\section{RESULTS}

In the study population comprising 153 pregnant women, the mean maternal and gestational age of patients was found to be $26.6 \pm 4.3$ years and $38.5 \pm 1.7$ weeks respectively. Majority $(62.7 \%)$ of the cases were primigravidas and more than half $(55.56 \%)$ of participants had their gestational age between 37 weeks 39 weeks +6 days. Out of the high risk pregnancies analyzed, as shown in Figure 1, Hypertensive disorders of pregnancy accounted for $38.5 \%$ of cases, followed by post dated pregnancies $(29.4 \%)$. Vaginal delivery was the result in $90(58.8 \%)$ subjects. Among the 153 cases analyzed, $17 \%$ and $9.1 \%$ had abnormal FBP and RBP scores, respectively.

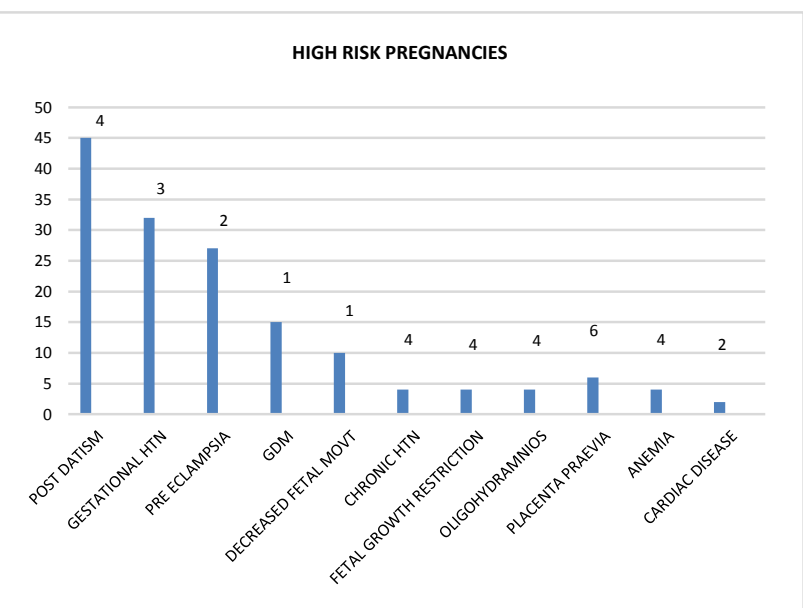

Figure 1: Indication for antepartum fetal surveillance.

Correlation among scores of RBP and FBP using Spearman's correlation coefficient was found to be 0.62 and it was statistically significant $(\mathrm{p}<0.0001)$ as shown in table 3. Correlation of individual components of FBP with RBP in patients who had abnormal FBP score generated few interesting results. Among 26 patients who had an abnormal FBP score, 16 cases had non-reactive NSTs out of which 9 had abnormal RBP score. The correlation between NST and RBP in patients with an abnormal FBP proved to be $r_{s}=0.46$ and statistically significant (p 0.01). In this study, only 1 case had an abnormal RBP score in spite of having a reactive NST. Baby was delivered through caesarean done in view of severe IUGR and oligohydramnios, and no adverse pregnancy outcome was noted. In the 26 cases with abnormal FBP score, 18 subjects had abnormal score for fetal movements and only 7 had an abnormal RBP score. The correlation was found to be $r_{s}=0.013$ (p 0.94) and hence not statistically significant. Among the same 26 cases comparison of fetal tone, fetal breathing score with RBP score revealed a negative correlation of $r_{s}=-0.118(p$ $0.56)$ and $r_{s}=-0.224$ ( $\left.p \quad 0.27\right)$ respectively and hence devoid of any statistical significance.

Table 3: Correlation between FBP and RBP.

\begin{tabular}{|llll|}
\hline RBP & FBP - & FBP - \\
Normal & Abnormal & \\
\hline Normal & 123 & 16 & 139 \\
\hline Abnormal & 4 & 10 & 14 \\
\hline & 127 & 26 & 153 \\
\hline
\end{tabular}

(FBP - full biophysical profile, RBP - rapid biophysical profile)

Taking Apgar score at 1 minute $\leq 7$ as an adverse outcome, $18(11.7 \%)$ cases had a low Apgar score. The correlation of scores of FBP, RBP with low Apgar at 1 minute was found to be $r_{s}=0.25(p$ 0.001) and $0.47(p<0.0001)$ respectively. Apgar score at 5 minutes $\leq 7$ was taken as the second adverse outcome and number of cases meeting this criteria were 14 (9.1\%). The correlation of scores of FBP, RBP with low Apgar at 5 minutes was worked out to be $r_{s}$ $=0.19(\mathrm{p} 0.01)$ and $0.35(\mathrm{p}<0.0001)$ respectively and revealed the fact that correlation of abnormal RBP with Apgar at 1 minute and 5 minutes was better than that with abnormal FBP. The need for NICU admissions was taken as the last adverse outcome. In the present study 24 neonates required NICU admissions out of which prematurity being most common indication with 10 $(41.7 \%)$ cases followed by meconium aspiration syndrome in $6(25 \%)$ cases. In the present study rapid biophysical profile proved to have a sensitivity of $71.42 \%$, specificity of $87.05 \%$, positive predictive value of $35.71 \%$ and negative predictive value of $96.80 \%$ for predicting all adverse perinatal outcomes put together.

Table 4: Correlation between RBP and adverse perinatal outcome.

\begin{tabular}{|llll|}
\hline $\begin{array}{l}\text { Adverse } \\
\text { outcome }\end{array}$ & $\begin{array}{l}\text { RBP - } \\
\text { Normal }\end{array}$ & $\begin{array}{l}\text { RBP - } \\
\text { Abnormal }\end{array}$ & \\
\hline Present & 121 & 10 & 131 \\
\hline Absent & 18 & 4 & 22 \\
\hline & 139 & 14 & 153 \\
\hline
\end{tabular}

(RBP - rapid biophysical profile, Adverse perinatal outcomes include low Apgar score at 1,5 minutes or NICU admission)

\section{DISCUSSION}

The FBP as a non-invasive, very accurate and applicable antenatal method to all patients is particularly attractive 
since it provides immediate individual results, does not provoke fetal distress. FBP has a low false positive rate and consists of acute markers of fetal hypoxia (fetal breathing, fetal movement, fetal tone, and FHR reactivity), and a chronic marker of fetal hypoxia that gives a better notion of uteroplacental reserve (AFI). However, there are disadvantages of this test. FBP is time-consuming as it includes at least a 30 minutes observation period of fetal biophysical activities and NST, which requires 20-40 minutes. Moreover, an expensive fetal heart rate monitor and an experienced interpreter is needed. RBP is simpler, inexpensive, and is faster. It has been developed to evaluate fetal well being when an NST machine is unavailable. The present study has demonstrated a correlation between RBP and FBP test and is very similar to results obtained by Phattanchindakun et al. ${ }^{4}$ Taking individual biophysical variables and comparing them with RBP in cases where the subject had an abnormal FBP score, only NST was found to have a statistically significant positive correlation with RBP. AFI, the chronic hypoxia indicator, and SPFM, the acute fetal hypoxia marker, have been thoroughly examined by the RBP. Keeping low Apgar score at 1 and 5 minutes and NICU admissions as adverse perinatal outcome, the sensitivity, specificity, positive predictive value, negative predictive value of RBP in predicting adverse pregnancy outcome when all three outcomes were taken together was found to be $71.4 \%$, $87.1 \%$, $35.7 \%$. $96.8 \%$ respectively. Owing to the differences in sample size and indications for fetal assessment, earlier studies by Chousawai et al. ${ }^{5}$, Tongprasert et $\mathrm{al}^{2}$ have shown wide variations in the statistical parameters of Rapid BPP. In spite of the variations the obtained data encouraged the use of RBP as an alternative antepartum test to evaluate the fetal well-being. In particular, its simplicity, shorter duration, no obligation of NST, or experienced interpreter makes the RBP a good choice for the obstetric center that is rather crowded or limited in experienced NST interpreters. In addition, the RBP does not need expensive high-resolution ultrasound equipment. If this technique is applied as a screening fetal test in rural areas, it will help in reduce the number of referral cases for FBP in tertiary care centers. However, the accuracy of RBP test (in terms of sensitivity, specificity, false positive, and false negative rates) should be extensively verified and a larger number of studied populations including more abnormal tests need to be investigated. This instrument produces the specific quality of sound with $110 \mathrm{~dB}$ of loudness and the frequency of $80 \mathrm{MHz}$. Despite its high efficacy, other inexpensive instrument that can generate the same quality of sound should be invented and studied to reduce the cost further.

\section{CONCLUSION}

With the positive correlation of rapid BPP with full BPP and its ability to predict adverse outcome, rapid BPP can be used as a good screening test for high risk pregnancies in busy obstetric setups where lack of experienced personnel and advanced equipment for surveillance is the main limitation. In case of an abnormal rapid BPP we suggest that the patient be subjected to a NST and followed up with FBP. As only those few patients who have an abnormal RBP score need to be subjected to further intensive surveillance, it saves a lot of time and energy.

\section{Funding: No funding sources \\ Conflict of interest: None declared \\ Ethical approval: The study was approved by the Institutional Ethics Committee}

\section{REFERENCES}

1. Manning FA, Morrison I, Lange IR, Harman CR, Chamberlain PF. Fetal assessment based on fetal biophysical profile scoring: experience in 12,620 referred high-risk pregnancies. I. Perinatal mortality by frequency and etiology. Am J Obstet Gynecol. 1985;151:343-5.

2. Tongprasert F, Jinpala S, Srisupandit K, Tongsong T. The rapid biophysical profile for early intrapartum fetal well-being assessment. Int J Gynaecol Obstet. 2006;95:14-7.

3. Tongsong T, Piyamongkol W, Anantachote A, Pulphutapong K. The rapid biophysical profile for assessment of fetal well-being. J Obstet Gynaecol Res. 1999;25:431-68.

4. Phattanchindakun B, Boonyagulsrirung $\mathrm{T}$, Chanprapaph P. The correlation in antepartum fetal test between full fetal biophysical profile and rapid biophysical profile. J Med Assoc Thai. 2010;93(7):759-64.

5. Chousawai S, Tongprasert F, Yanase Y, et al. The efficacy of rapid biophysical profile in predicting poor pregnancy outocmes in suspected intrauterine growth restriction fetuses:preliminary study. J Med Assoc Thai. 2012;95(4):482-6.

Cite this article as: Prabhu AV, Mahale N, Mahale A. The correlation between full biophysical profile and rapid biophysical profile in antepartum fetal surveillance. Int J Reprod Contracept Obstet Gynecol 2015;4:1086-9. 